associated with mortality (HR 0.646, 95\% CI 0.135-3.097, $\mathrm{p}=0.585)$. On stepwise forward regression analysis, only undergoing any intervention (TAVI or AVR) remained a significant predictor of increased survival (HR 0.308, 95\% CI 0.159-0.597, $\mathrm{p}<0.001$ ) (table 1). ST2 (HR 1.020, 95\% CI 1.003-1.037, $\mathrm{p}=0.022$ ) and LnNT-proBNP (HR 1.285, 95\% CI $1.036-1.594, \mathrm{p}=0.022$ ) were the only significant predictors for poor mortality (table 1 ).

Discussion Higher volume of EAT indexed to myocardial mass was not associated with mortality in patients with AS. The variables that did remain significant after adjustment were ST2, NT-proBNP and undergoing intervention.

Conclusions Higher EAT volume indexed to myocardial mass was not significantly associated with mortality after adjusting for other variables in patients with AS.

Conflict of Interest None

\section{INHERITED CARDIOMYOPATHY CONDITIONS CLINIC IN DISTRICT GENERAL HOSPITAL IMPROVES ESC GUIDELINES IMPLEMENTATION AND MANAGEMENT OF PATIENTS WITH HYPERTROPHIC CARDIOMYOPATHY}

Elton Luo, Kenneth Chan, Joyee Basu, Lindsey Tilling, Katrin Balkhausen, Sacha Bull. Royal Berkshire Hospital, Reading, UK

\subsection{6/heartjnl-2021-BCS.27}

Background Hypertrophic cardiomyopathy (HCM) is the most common inherited cardiomyopathy and is frequently encountered in clinic. In many district general hospitals (DGH), the condition is frequently managed in general cardiology clinics with a small proportion referred to dedicated Inherited Cardiomyopathy Conditions (ICC) clinic in tertiary centres for complex treatments. We hypothesised that management of HCM patients would be improved by introduction of a dedicated ICC clinic at our district general hospital.

Purpose The purpose of the study was to evaluate the impact on patient management in a dedicated ICC clinic at our district general hospital. The outcome was determined by assessing adherence to the European Society of Cardiology (ESC) HCM guidelines before and after introduction of this clinic, hospital admission and mortality.

Methods We retrospectively reviewed the clinic records of patients with a diagnosis of HCM seen in the general cardiology clinic. A dedicated ICC clinic was established and the patient records of those with HCM assessed in the ICC clinic over a 6-month period were also reviewed. Patient assessment and management were evaluated against ESC recommendations, including clinical risk stratification (symptoms review, ambulatory blood pressure monitoring, 48-hour Holter monitoring, sudden cardiac death (SCD) risk assessment); imaging assessment by echocardiography and cardiac magnetic resonance (CMR); and patient counselling (exercise, genetic, and family counselling). Patient outcomes at 2-years were evaluated, including hospital admissions from cardiac causes (arrhythmia, stroke, chest pain, heart failure); new onset heart failure; SCD and all-cause mortality.

Results Demographics were similar for HCM patients assessed in the ICC clinic $(n=62$, mean age $61 \pm 13)$, and general cardiology clinic prior to the introduction of 1CC clinic $(n=24$, mean age 61 \pm 17 ). There were significant improvements in risk stratification by clinical assessment of symptoms, holter monitoring, as well as formal SCD risk evaluation (table 1).
Abstract 27 Table 1 Demographics and clinical risk stratification of HCM patients assessed in local Inherited Cardiomyopathy Conditions clinic compared to general cardiology clinic

\begin{tabular}{llll}
\hline & $\begin{array}{l}\text { ICC clinic } \\
(\mathbf{n}=62)\end{array}$ & $\begin{array}{l}\text { General cardiology clinic } \\
(\mathbf{n}=24)\end{array}$ & $\begin{array}{l}\text { P- } \\
\text { value }\end{array}$ \\
\hline Age & $61 \pm 13$ & $61 \pm 17$ & 0.43 \\
Male gender & $39(62 \%)$ & $18(75 \%)$ & 0.15 \\
$\begin{array}{l}\text { linical risk stratification } \\
\text { Symptoms review }\end{array}$ & $62(100 \%)$ & $15(62.5 \%)$ & $<0.001$ \\
$\begin{array}{l}\text { Ambulatory BP monitoring } \\
\text { performed }\end{array}$ & $13(21 \%)$ & $2(8.3 \%)$ & 0.17 \\
$\begin{array}{l}\text { 48-hr holter performed } \\
\text { Exercise tolerance test }\end{array}$ & $60(96.8 \%)$ & $7(29.2 \%)$ & $<0.001$ \\
performed & $31(50 \%)$ & $7(29.2 \%)$ & 0.08 \\
SCD-risk score evaluated & $31(50 \%)$ & $1(4.2 \%)$ & $<0.001$ \\
\hline
\end{tabular}

Abstract 27 Table 2 Imaging, patient management and 2-year clinical outcome of HCM patients assessed in local Inherited Cardiomyopathy Conditions clinic compared to general cardiology clinic

\begin{tabular}{|c|c|c|c|}
\hline & $\begin{array}{l}\text { ICC clinic } \\
(n=62)\end{array}$ & $\begin{array}{l}\text { General cardiology clinic } \\
(n=24)\end{array}$ & $\begin{array}{l}\text { P- } \\
\text { value }\end{array}$ \\
\hline \multicolumn{4}{|l|}{ Imaging and patient management } \\
\hline LVOT gradient measured & $59(95.2 \%)$ & $19(79.2 \%)$ & 0.02 \\
\hline CMR imaging & $46(74.2 \%)$ & $12(50 \%)$ & 0.03 \\
\hline Family counselling (female, aged & $1(\mathrm{~N}=7)$ & $0(\mathrm{~N}=1)(0 \%)$ & 0.69 \\
\hline$<52)$ & $(14.3 \%)$ & & \\
\hline Genetic counselling & $13(21 \%)$ & $2(8.3 \%)$ & 0.17 \\
\hline \multicolumn{4}{|l|}{$\begin{array}{l}\text { Clinical outcomes at 2-year } \\
\text { follow up }\end{array}$} \\
\hline Cardiac care admissions & $1(1.6 \%)$ & $3(12.5 \%)$ & 0.03 \\
\hline New onset heart failure & $7(11.3 \%)$ & $6(25 \%)$ & 0.11 \\
\hline All-cause mortality & $1(1.6 \%)$ & $1(4.16 \%)$ & 0.48 \\
\hline
\end{tabular}

There was better compliance with ESC recommendations in imaging assessments; more patients underwent CMR and left ventricular outflow tract (LVOT) assessment in echocardiography in the ICC clinic cohort (table 2). None of the patients in either cohort met the clinical endpoint of SCD. Hospital admission from cardiac causes at 2-years was significantly lower in the patients assessed in ICC clinics (table 2).

Conclusion In this HCM cohort, introduction of a local ICC clinic led to improved patient care through better adherence to ESC HCM guidelines in particular with respect to clinical assessment, imaging and risk stratification as well as reduced hospitalisations from cardiac causes.

Conflict of Interest None

\section{AUTOMATIC AORTIC ANNULUS SIZING BY THE HEART NAVIGATOR III SOFTWARE IN THE PLANNING OF TRANSCATHETER AORTIC VALVE IMPLANTATION (TAVI)}

${ }^{1}$ Elliott Carande, ${ }^{1}$ Alexander Chase, ${ }^{1}$ Ahmed Hailan, ${ }^{1}$ Ayush Khurana, ${ }^{1}$ Dave Smith, ${ }^{2}$ Daniel Obaid. 'Swansea Bay University Health Board, Swansea, UK; ${ }^{2}$ Swansea Bay University Health Board, Swansea University Medical School

10.1136/heartjnl-2021-BCS.28 